\title{
A Case Study on the Influence of Chinese Regional Dialects to English Vowel-Nasal Pronunciation and Correction
}

\author{
Qi Wu $\mathbf{u}^{1,2}$ \\ ${ }^{1}$ School of Foreign Languages, Jiujiang University, Jiujiang, China \\ ${ }^{2}$ Department of English Language \& Literature, Dong-A University, Busan, South Korea \\ Email:wuqiqiwu@126.com
}

How to cite this paper: Wu, Q. (2020) A Case Study on the Influence of Chinese Regional Dialects to English Vowel-Nasal Pronunciation and Correction. Open Access Library Journal, 7: e6800.

https://doi.org/10.4236/oalib.1106800

Received: September 7, 2020

Accepted: September 26, 2020

Published: September 29, 2020

Copyright $\odot 2020$ by author(s) and Open Access Library Inc.

This work is licensed under the Creative Commons Attribution International License (CC BY 4.0).

http://creativecommons.org/licenses/by/4.0/ (c) (i) Open Access

\begin{abstract}
A few studies have examined phonetic variation among EFL learner vowels and consonants-mainly college students and middle school students-from southern or northern China dialects [1] [2] [3]. This study will continue to focus on an experienced English learner-an university English teacher of Jiangxi province in South China-to test such hypothesis that whether there exist some acknowledged pronunciation errors especially in uttering some certain English vowel(s) and nasal consonant(s) and further there is a kind of role the speaker's southern China dialect plays in pronouncing them. This is posed under the assumption that the expected pronunciation acoustic characteristics will be acoustically and perceptually affected by regional dialect. The results suggest that these differences may be less related to non-native speakers' English-language experience and more related to differences in both the configuration of the vocal tract and vowel duration.
\end{abstract}

\section{Subject Areas}

Linguistics

\section{Keywords}

Southern China Dialect, English Vowel(s) and Nasal Consonant(s), Acoustic Characteristics, Pronunciation and Correction

\section{Introduction}

Chinese EFL learners often encounter some difficulties in acquiring English pronunciation, and one of the significant reasons is that English has much more 
phonemes and syllables than Chinese and the classification of English vowels is more delicate than that of Chinese. The phonological system of Chinese is very different from that of English. Some English phonemes do not have Chinese counterparts and are hard to learn. Others resemble Chinese phonemes but are not identical to them in pronunciation, and thus can cause some confusion. Notably, some difficulties exist in some vowels, consonants, stress, intonation, etc..

To contrast mandarin Chinese and Standard British English (Received Pronunciation, RP), it is necessary for us to have some ideas about these two languages' vowel systems by comparing them.

The number of Chinese vowels is $6(\mathrm{i}, \mathrm{u}, \dot{\mathrm{u}}, \mathrm{e}, \mathrm{o}, \mathrm{a})$ and is just half of that of 12

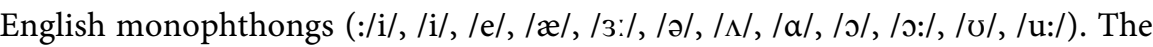
basic vowel system configuration of Chinese is a triangle with opposite opening degrees, except for the most open vowels, other vowels in the tone degree from oppositions (oral backness and tip roundness). The basic configuration of English forms a square, open contrast between tone degree and sound length. Chinese vowels have more variants and assume more complex functions. For instance, thought the Chinese " $i$ " and the English "i:" and " $i$ / I" all belong to the same close unrounded front vowels, it is apparent that the Chinese " $i$ " has a little higher and more fronting tongue position than that of the English " $\mathrm{i}:$ " and " $\mathrm{i} / \mathrm{I}$ ", and when the Chinese " $i$ " is pronounced the tongue tip slightly touches the alveolar back, causing some slight friction. In addition, in Chinese, there is not such half-open half-close front vowel /e/ or / $/$ /. During articulating the English /ei/ or /e I/, the tongue needs to move a little backward while the Chinese "ei" is pronounced by moving the tongue a little forward. Some research finds that /i:/ is often pronounced as the "ei[ei]" and / I/ as ei[ei], /ai/, i[i], and the error percentage of long " $i$ " is higher than that of the short " $\mathbf{I}$ ".

Tiee [4] does an important research on comparing monosyllabic structure of American English and Mandarin Chinese. He claims that there are many similarities and differences between the two sound systems. For instance, in Mandarin Chinese there is no pair like /i:/ and /I/, which is quite difficult for Chinese learners to identify. Tiee [4] adds that the-high-front-spread vowels in the two languages are different since in the English /i:/ the tongue is glided upwards, while in Chinese it is steady in high-front position, without any glide at all. The English front vowels /I/ and/e/ tend to be very difficult for adult Mandarin Chinese speakers to pronounce.

Juffs [5] analyzes Chinese learners' stress errors in English pronunciation, and concludes that these errors may be influenced by L1. He suggests that the importance of tone in Mandarin Chinese results in Chinese learners' errors in stress, because they regard stress as tone when they speak English. Therefore, they have strong consciousness of tonic syllables and ignore pitching the height on the word level.

Moreover, specifically, when the individuals (including college/university 
English teachers) from the South and the North of China produce some sounds, the tongues are different in high, low, front and back places. For example, in the case of nasal sounds $/ \mathrm{m} /, / \mathrm{n} /, / \mathrm{n} /$, many southern students have great difficulty with these three nasal sounds. The influence of local sounds not only hinders the correct pronunciation of Chinese sounds but also of individual English sounds. For example, some peoples and even teachers tend to confuse the nasal /n/ with the lateral /1/ and mispronounce "night life" as a "light knife".

The effect of regional dialect on acoustic characteristics of vowels has been proven significant [6] [7] [8]. Cross-dialectically, this research aims to study some characteristics of a university English teacher's pronunciation of some certain vowels and consonants, which will be conducted between Mandarin Chinese and British English. The expected pronunciation errors are: 1) the Chinese /i/ and the English /i:/ and /I/;2) the Chinese /ei/ and the English /e I/; 3) the consonants $/ \mathrm{n} /$ and $/ 1 / 44$ ) the stress. The analysis will be done in the following Discussion Part, where some suggestions for teaching methods, material, and activities will be provided.

\section{Subject and Procedure}

\subsection{Subject's Language Background Information}

The subject, female, graduated from the English Department of the School of Foreign Languages of Yunnan University ("Top 100" among over 1000 universities and colleges in China) in 2004 with a Bachelor of Arts degree and passed TEM8 (Test for English Majors-The most advanced level of comprehensive English ability test in China). In 2013, she obtained a master's degree in literature from Nanchang University ("Top 100" among over 1000 universities and colleges in China). She is mainly engaged in teaching "Basic English", "Comprehensive English", "College English" and other courses. She twice won the second prize of the "Learning Star" teaching competition of the "Shanghai Foreign Language Education Press"; she won the second and third prizes of the provincial teaching competition for many times, and the first prize of the school-level teaching competition once. Between September 2017 and August 2018, she was funded by the "National Key Teachers" project of the China Scholarship Council and went to the Central University of Washington for a one-year study on the second language acquisition. Therefore, the adult subject, now 35, is very excellent in English teaching and speaking as well-who can be regarded as a well-experienced or advanced English learner in China.

\subsection{Recording Procedure and Recording Material}

Subject's micro-class (a type of mini-lesson with around 15 - 20 minutes) is recorded by using a mobile phone. This class is designed for English majors by means of PPT with the topic "Euphemism" and the period is about 14:30 minutes during which the subject speaks English a little fast with the interactive activities being constructively organized. 
Because of the nature of such micro-class (the teaching content is English grammar "Subjunctive Mood", and the number of students is 35) with a time limit of not more than 20 minutes, the subject is a little nervous and hasty to teach the material (much rich content) especially with a recorder sitting in the classroom, which greatly reduces the frequency and length of interactive activities among teacher-student and student-student and may result in the subject's pronunciation errors(s) without enough attention to avoiding possible dialect's influence.

\section{Result}

The selected pronunciation errors with examples are:

1) A vowel pronunciation problem-dynasty /'dainəsteI/ $\rightarrow$ /'dainəstíi (correct)

2) A word stress problem-uniform /junı'fo:m/ $\rightarrow$ /'ju:nıfo:m/ (correct)

3) A /l/ consonant problem-consult /kən's $\underline{\text { nt }} /$ / $\rightarrow$ /kən's $\Lambda \underline{l}$ t/ (correct)

In short, there are really few errors in her English speaking. However, although the number is very limited, the selected three errors reflect a relatively general tendency not only among university/college English teachers but also in Chinese students as English majors and non-English majors as well as in other Chinese EFL learners.

\section{Discussion}

\subsection{Speculated Reasons for Dynasty /'dainəsteI/ $\rightarrow$ /'dainəsti /}

1) The height of the tongue and jaw

Closing diphthong /eI/ begins at /e/ and glides to /I/; /e/ is a mid-front vowel, with the tongue half-raised in the mouth so that it is between the positions of being half-close and half-open; /I/ is a (less)front, close unrounded vowel, with the lips slightly spread; by contrast, /i/ is intermediate between long /i:/ and short $/ \mathrm{I} /$, being hard to be perceived by some native speakers because it is not phonemically distinctive-(more) fronting, close unrounded lax vowel (/i:/ is a front close unrounded tense vowel). Therefore, even as an English teacher, it is still very hard to distinguish/identify or acquire it. Whereas, though the front vowel /e/ in English is also absent in Mandarin, it has a distinctive contrast to Chinese [e] which is also a same middle but central vowel and has a different sound. Meanwhile /I/ can be ascertained and acquired by an EFL learner in a relatively easier way so that such acquisition is so strongly rooted in a learner's mind that the English /i/ can be filled out/ substituted by using it automatically or unconsciously.

2) Presence of contrast

The length contrast between long and short vowels in English does not exist in Mandarin, like "ship" and "sheep" (/i:/\&/I/). Therefore, Chinese English learners are not naturally aware of the duration difference of the vowels in English and may not even produce or perceive those differences. However, the Chinese [ei] that tends to move forward as a front-sounding diphthong has its roughly cor- 
responding sound unit/ei/ as a similar front-sounding diphthong that tends to move backward, though the ending /i/ and / $/$ / have some sort of difference which can be actually ignored for its vagueness or non-arrival in fast speech without causing a wrong sound or communication problem.

3) /t/'s influence on / $y /$ in "-ty"

The point of articulation of alveolar consonant " $\mathrm{t}$ " is situated near the alveolar ridge, which is the area lying between the upper front teeth and the palate. If the unstressed syllable "-ty" in dynasty is pronounced correctly-that is [ti], then the lips should be relaxed and the central/front area of the tongue should be in the central/high area of the mouth for this sound. The overall neutrality and relaxed tongue and lip position is why it is one of the pronunciations used in an unstressed vowel position. In other words, if the lips are open enough and at the same time the tongue is leaving apart from the upper teeth and the palate to the middle-front position (and /or glides to a slightly more close position), the sound [tei] will be made instead of [ti]. Here, the relevant factor is the fact that the first syllable of dynasty is stressed, thus the final syllable is unstressed in a more irregularly relaxed way.

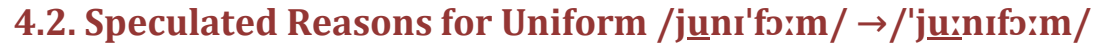

1) Overgeneralization of the stress on word and affix

The content word "form" is regularly stressed. However, it doesn't mean that any content word combined with other units such as affixes always remain the same stress pattern. Here, the noun "uniform" is a three syllable word, where there is a tendency to put the stress towards the front of the word for such type of nouns. Another factor that is easily overgeneralized by Chinese EFL learners is the less important or unstressed roles of affixes which, in fact, can have three possible effects on word stress: the affix is stressed, the affix has no effect, the affix is not stressed but on the stem moves [9]. Of course, "uni" is a prefix and it may belong to the third possibility. Multisyllabic words often vary in their stress patterns. In English, nouns more likely have stress on the initial syllable while verbs have stress on the ultimate syllable [10] [11].

2) Mispronunciation and perception of vowel

Mispronunciation of vowel indicates that Chinese EFL learners pronounce the vowels incorrectly, which results in the wrong stress placement. As can be observed, the word Uniform that is wrongly stressed has another problem because its first syllable contains the long /u:/, which normally gets stress (together with $/ \mathrm{ni} /$ ). But the subject pronounced this word as [junI'fo:m], thus giving the first syllable the less prominent stress, which automatically switched the stress to the last heavy syllable. It shows that the vowel mispronunciation influences the placement of stress.

Regarding vowel production, vowel duration also plays a role in perceptual vowel identification and overall speech intelligibility [12] [13] [14]. As for the contributors to vowel reduction for short or lax vowels, vowel duration was a 
key determinant in whether a speaker would undershoot articulatory placement of a target vowel [15]. This is important because articulatory undershoot has effects on decreasing perceived speech intelligibility.

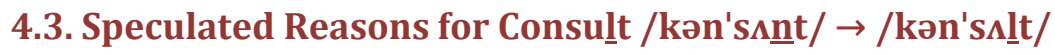

1) Inadequate knowledge of /l/

The $/ \mathrm{n} /$ is a nasal sound and the airflow moves through your nose. The /l/ is a liquid sound and the airflow moves along the sides of your tongue. Many Chinese EFL learners often confuse /l/ for / $\mathrm{n} /$ mainly because the English /1/ has no equivalent in Chinese. In Mandarin Chinese, the /1/ sound exists but is prosodically restricted. The /l/ can only appear syllable-initially, which means that a Chinese speaker would have more trouble with an /1/ sound at the end of a word, like saying the /1/-sound in "ladder" than in "feel". And the /1/-sound in "ladder" is light and the /l/-sound in "feel" is dark (velarized sound). Here, the /l/-sound in word consult /kən'sslt/ is actually also a dark sound / $1 /$. This is a fact that English language has distinct /l/ and / $\mathbf{t} /$ phonemes, functioning just as allophonic variants depending on whether it is in the beginning of the syllable or the end of the syllable.

2) [n]'s coarticulation influence

Similarly, since the Chinese consonant [1] is only articulated at the beginning of a syllable, some Chinese EFL learners exhibit a tendency to replace the final [1] (or a [1] after a vowel) with a nasal like [n]. As a result, the [1] or [1] in the word "consult" is substituted by the sound [n]. A lot of people with different dialects in China have trouble with "l" and " $n$ ", and they cannot differentiate "lan" and "nan". It is a little strange that in such blurring sounds the nasal sound [n] has more tendency to be pronounced which means it is relatively more approachable in general. This also includes modeling coarticulation [16] in vowel-nasal syllables.

\subsection{Suggested Teaching Methods, Materials, and Activities}

1) Enhancing the manner and place of articulation with contrastive examples

According to House [17], vowel duration varies depending on the manner in which a vowel is produced (e.g., tense versus lax). The manner of articulation of the Mandarin Chinese /i/ and the English /eI/ (including long /i:/and short/i/ or $/ \mathrm{I} /$ ) as well as the place of articulation of consonants such as $/ \mathrm{l} / \mathrm{and} / \mathrm{n} /$ should be distinguished and identified by instructing learners to do contrastive practice. According to the discussion mentioned above, in the process of acquiring vowels, in the case of pronouncing /i/ into /eI/, an effective method is that some contrastive examples can be chosen, for instance, peel /pi:l/ and 培/pei/, 笔/bi/ and pay/peI/, 离/li/ and 类/lei/, fail/feil/ and feel/frl/, male/meil/ and meal/mil/, dale/derl/ and deal/dil/, fate/fert/ and feet/fit/, etc..

Teachers need to help the learners drop the nasality when attempting to produce that sound as well as free the sides of the tongue while keeping contact be- 
tween the tip and the alveolar ridge. However, when /1/ occurs at the end, it just sounds like [o] as Chinese learners move their lips forward. Students need to be told to keep their lips back and to focus only on the tongue movement.

/l/ (initial): light; lace; lead; laugh; learn

/1/ or /1/ (medial): fault; rolling; falling; swollen; really

/1/ or /1/ (final): recall; fall; roll; available; identical

2) Teaching systemic knowledge with the help of advanced technology

The non-native subjects' degrees of accuracy in producing and perceiving English vowels were related [18]. As to the problems in assigning stress, especially to the three-syllable words, more attention should be given to the learning of knowledge of rules on English word stress, and the learners' insensitivity to syllabic structure of English words. A Chinese scholar Liu [19] suggests that Chinese tones count more in determining the meaning of words than stress, so developing the ability to discriminate and perceive the difference between the stressed and unstressed syllables of English words. In addition, some speech analysis software can help provide visual feedback for L2 segmental and suprasegmental production in pronunciation instruction. Much knowledge is needed o characterize vowels based on time-varying articulatory characteristics and quantify tongue and lip movement time series [20] [21]. Using audiovisual feedback is a more efficient 11 way to train learners to discriminate contrastive sounds between L1 and L2 than the audio-only method [22]. A growing body of research has shown that the implementation of advanced technology (such as TF32 software) can be used to separate each speech sample into audio clips of vowels/consonants to complete acoustic analysis [23]. Differences that can be attributed solely to dialectical differences may be easier to determine by using measurements that do not assume articulatory equivalency.

\section{Conclusions}

The lack of some English vowels notably influences the pronunciation of even experienced English teachers in China's universities. It is also noteworthy considering that speakers of Southern China dialect are often perceptually identified to utter more often than northern speakers, which is a well acknowledged fact in relevant research findings. However, patterns of differences found between these dialects, indicate that articulatory placements for vowels and nasals production may be dependent on the dialect of the speaker.

This study's contribution is that several characteristics of vowels and nasals spoken by speakers of a Southern China dialect are proved to be consistent with that of mainstream EFL learners' dialects across southern China. Comparison of vowels and consonants spoken by university teachers of many other Southern China dialects and even northern China dialects, according to current literature, has revealed the presence of a dialectical difference for certain parameters. The limit of this study does not provide other comparative evidences (but just based on current results) to indicate that some differences may be related to differenc- 
es in both the configuration of the vocal tract and vowel duration, which suggests not only are there differences between the northern and southern dialect regions, but there are also differences within southern regions, which will be surveyed in future study. In addition, applying statistic methods to drive a data-based quantitative analysis for dialect-influenced experienced teacher's articulation of vowels and nasals will be investigated as future directions.

\section{Conflicts of Interest}

The author declares no conflicts of interest regarding the publication of this paper.

\section{References}

[1] Zhang, J.S. (2002) A Comparative Study of English and Chinese Vowels and Its Pedagogical Significance. Journal of PLA University of Foreign Languages, 25, 56-59.

[2] Kong, H.-F. (2009) A Survey of English Vowel Pronunciation among College Students of Hefei Natives. Journal of Hefei University (Social Sciences), 26, 36-39.

[3] Kong, G.-Y. (2016) An Contrastive Analysis on Mandarin and English Pronouncing Errors in Cantonese Region. Overseas English, 4, 9-11.

[4] Tiee, H.H. (1969) Contrastive Analysis of the Monosyllable Structure of American English and Mandarin Chinese. Language Learning, 19, 1-16. https://doi.org/10.1111/j.1467-1770.1969.tb00929.x

[5] Juffs, A. (1990) Tone, Syllable Structure and Interlanguage Phonology: Chinese Learners' Stress Errors. International Review of Applied Linguistics, 28, 99-117. https://doi.org/10.1515/iral.1990.28.2.99

[6] Clopper, C.G. and Pierrehumbert, J.B. (2008) Effects of Semantic Predictability and Regional Dialect on Vowel Space Reduction. Journal of the Acoustical Society of America, 124, 1682-1688. https://doi.org/10.1121/1.2953322

[7] Fox, R.A. and Jacewicz, E. (2009) Cross-Dialectal Variation in Formant Dynamics of American English Vowels. Journal of the Acoustical Society of America, 126, 2603-2618. https://doi.org/10.1121/1.3212921

[8] Jacewicz, E., Fox, R.A. and Salmons, J. (2011) Regional Dialect Variation in the Vowel Systems of Typically Developing Children. Journal of Speech, Language, and Hearing Research, 54, 448-470. https://doi.org/10.1044/1092-4388(2010/10-0161)

[9] Pamela, R.R. (2011) English Phonology and Pronunciation Teaching. Continuum International Publishing Group, London.

[10] Kelly, M.H. and Bock, J.K. (1988) Stress in Time. Journal of Experimental Psychology: Human Perception and Performance, 14, 389-403. https://doi.org/10.1037/0096-1523.14.3.389

[11] Davenport, M. and Hannahs, S.J. (2005) Introducing Phonetics and Phonology. 2nd Edition, Oxford University Press, London.

[12] Mok, P.K. (2011) Effects of Vowel Duration and Vowel Quality on Vowel-to-Vowel Coarticulation. Language and Speech, 54, 527-545.

https://doi.org/10.1177/0023830911404961

[13] Ferguson, S.H. and Kewley-Port, D. (2007) Talker Differences in Clear and Conversational Speech: Acoustic Characteristics of Vowels. Journal of Speech, Language, and Hearing Research, 50, 1241-1255. 
https://doi.org/10.1044/1092-4388(2007/087)

[14] Lindblom, B. (1963) Spectrographic Study of Vowel Reduction. Journal of the Acoustical Society of America, 35, 1773-1781. https://doi.org/10.1121/1.1918816

[15] Tjaden, K., Rivera, D., Wilding, G. and Turner, G.S. (2005) Characteristics of the Lax Vowel Space in Dysarthria. Journal of Speech, Language, and Hearing Research, 48, 554-566. https://doi.org/10.1044/1092-4388(2005/038)

[16] Birkholz, P. (2013) Modeling Consonant-Vowel Coarticulation for Articulatory Speech Synthesis. PLoS ONE, 8, e60603.

https://doi.org/10.1371/journal.pone.0060603

[17] House, A.S. (1961) On Vowel Duration in English. Journal of the Acoustical Society of America, 33, 1174-1178. https://doi.org/10.1121/1.1908941

[18] Flege, J.E., Bohn, O.-S. and Jang, S. (1997) Effects of Experience on Non-Native Speakers' Production and Perception of English Vowels. Journal of Phonetics, 25, 437-470. https://doi.org/10.1006/jpho.1997.0052

[19] Liu, D. (2017) The Acquisition of English Word Stress by Mandarin EFL Learners. English Language Teaching, 10, 196-201. https://doi.org/10.5539/elt.v10n12p196

[20] Wang, J., Green, J.R., Samal, A. and Marx, D. (2011) Quantifying Articulatory Distinctiveness of Vowels. Proceedings of InterSpeech, Florence, 27-31 August 2011, 277-280.

[21] Wang, J., Green, J.R., Samal, A. and Yunusova, Y. (2013) Articulatory Distinctiveness of Vowels and Consonants: A Data-Driven Approach. Journal of Speech, Language, and Hearing Research, 56, 1539-1551. https://doi.org/10.1044/1092-4388(2013/12-0030)

[22] Hardison, D.M. (2003) Acquisition of Second-Language Speech: Effects of Visual Cues, Context, and Talker Variability. Applied Psycholinguistics, 24, 495-522. https://doi.org/10.1017/S0142716403000250

[23] Milenkovic, P. (2001) TF32 [Computer Program]. University of Wisconsin-Madison, Madison. 